Original Article

\title{
ATTITUDE OF COLLEGE STUDENTS TOWARDS ALCOHOL CONSUM PTION IN MANGALORE
}

\author{
Deepak Daniel ${ }^{1}$, Devishri Shetty ${ }^{1}$, Greeshma Jilson Jose ${ }^{1}$, Haritha J ${ }^{1}$, Jeevan Ravi ${ }^{1}$, \\ Lakshmi S Pillai ${ }^{1}$, Anupa Neghandi ${ }^{1}$, Santhosh ${ }^{2}$ \& Rashmi Kundapur ${ }^{3}$ \\ ${ }^{1}$ Students, ${ }^{2}$ Medico Social Worker, ${ }^{3}$ Associate Professor, Department of Community M edicine, K. S Hegde Medical \\ Academy, Nitte university, M angalore, Karnataka, India. \\ Correspondence: \\ Rashmi Kundapur, \\ Department of Community Medicine, \\ KS Hegde M edical Academy, Nitte University, Mangalore - 575 018, Karnataka, India. \\ M obile : $+919880496567 \quad$ E-mail : dr.rashmi.kundapur@gmail.com
}

\begin{abstract}
:
Introduction : According to various studies conducted, the response of the adolescent towards alcohol is different. Attitudes ranged from acceptance that is to "easy to get" and is "just going to happen, "to personal responsibilities, it's your choice not to drink peer pressure; you end up drinking to be part of group".
\end{abstract}

Objectives: To assess the attitude of youngsters towards al cohol consumption.

Materials and methods : A survey was performed in colleges under NITTEUniversity. Students present at the time of visit were covered. A questionnaire was prepared comprising of a set of 14 questions covering the 3 main objectives of the survey.

Results : As per our survey of the 1150 students, $26.4 \%$ (304) students consume alcohol. Of these who consume alcohol, 188 (61.84\%) students felt it was safe to drink. Also a majority of 219 students (72.03\%) did not want to stop their drinking habits and $225(74.01 \%)$ students haven't tried quitting. Surprisingly, a good 1050 (91.30\%) out of 1150 students responded that they were aware of the harmful effects of alcohol consumption.

Conclusion : We have concluded that the students are well informed and they know the ill effects of alcohol consumption even though, most of them consider it as a part of life style.

Keywords: Attitude, alcohol consumption, youngsters, harmful effects

\section{Introduction :}

According to various studies conducted the response of the adolescent towards alcohol is different. Attitudes ranged from acceptance that is to "easy to get" and is "just going to happen, "to personal responsibilities, it's your choice not to drink peer pressure; you end up drinking to be part of group".

Generally they spoke of alcohol as a fact of life and part of growing up. It is Access this article online Quick Response Code

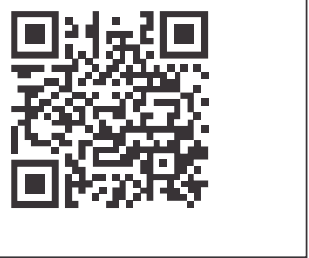

will relax them, 54.5\% think that they will be more open and friendly. $46.7 \%$ think that they will target problems if they drink. ${ }^{1} M$ any youngsters gave 3 most common reasons provided for why they started drinking were:- That friends did it and look like fun, A desire to experiment and see what it was like, Following the examples of family members and relatives

Many youngsters consume alcohol on a trail and error basis. Early teens and junior high were characterized as they have experimented on drinking. They consume alcohol from friends and peer who would often buy alcohol forthem.

The studies have also shown that exposure to alcohol advertising effects, youth's attitudes about alcohols role in society. 
Among elementary school children, exposure to beer commercials is related to beliefs about beer drinking and expectation to drink as adult. Most adolescents respond positively to television advertisements for alcohol and do not think the advertisements are boring. Many like adds that, Spotlight attractive model, M ake drinking look like fun Are in attractive, exotic settings, Make the product look good, Are humorous ${ }^{2}$

The effect of religion on the attitude of youth towards alcohol is also seen. It showed that students with no religious affiliation reported significantly high level of drinking frequency and quantity than those who are. Regular attendance at religious services is linked to healthy, stable family life and well behaved children.

Very few youngsters also showed following attitude towards alcohol. Alcohol influences traffic and results in road accidents, family problem and relationship violence and crime, health and financial problems ${ }^{3}$ Nearly half of them think that youth can be diverted to sports and leisure activities. They also think that they need more health information

M any think of joining various programmes against alcohol in youth.

\section{Objectives:}

To assess the attitude of youngsters towards alcohol consumption.

\section{M aterial and Methods:}

A survey was performed in colleges under NITTEUniversity. Students present at the time of visit were covered. A questionnaire was prepared comprising of a set of 14 questions covering the 3 main objectives of the survey. The students were asked to fill the questionnaire irrespective of their gender or whether they consume alcohol or not. The sample size used was 1150 students and the sampling method used is universal sampling. The responses were calculated \& tabulated. Also statistical analysis was done using proportions to know the prevalence, gender comparison, effects $\&$ attitude with regard to alcohol consumption.
Operational definitions:

1. ABUSE: It is called abuse when the consumer fails to fulfill role obligations at work, school or home. Physically hazardous situations to the consumers. They might have legal problems. Continued use alcohol despite serious social and interpersonal problems.

2. DEPENDENCE: Consumers have tolerance, withdrawal symptoms, persistent desire to cut down drinking. Great amount of time of consumers is spent with activity related to alcohol. Social, occupational or recreational activities are given up by dependents. Continued use despite of knowledge of serious social, psychological and physical problems.

3. Social Drinkers: This type of consumers drink slowly, know when to stop, does not drink to get drunk, never drives after drinking, they respect non-drinkers also knows and obeys laws related to drinking.

4. Binge Drinking: Consumption of five or more drinks at a single sitting for a man and four drinks at a single sitting for a woman.

5. Ever user: The respondent, who accepts having taken one or more mentioned substances ever in life.

6. Regular user: The respondent, who accepts having used one or more mentioned substances during past one year and has been taking it at least once a week or several times in the previous month.

\section{Result:}

As per our survey of the 1150 students, $26.4 \%$ (304) students consume alcohol. Of these who consume alcohol, $188(61.84 \%)$ students felt it was safe to drink. Also a majority of 219 students $(72.03 \%)$ did not want to stop their drinking habits and 225 (74.01\%) students haven't tried quitting. Out of 304 students, only 82 (26.97\%) students agreed to drive after drinking. Surprisingly, a good 1050 (91.30\%) out of 1150 students responded that they were aware of the harmful effects of alcohol consumption. Around $13(1.13 \%)$ students did not respond to the question.(Table-1) 
When asked about their attitude towards alcohol consumption, out of the 1150 students, most of the students believed that alcohol is a 'part of the lifestyle' ( 895 students; 294.4\%) followed by 'social evil' (586 students; $192.7 \%$ ) and a 'party element' (491students; 161.5\%). Also 242 students (79.6\%) believed that alcohol is used for pleasure and 241 students (79.27\%) felt that it is a stress buster. A minority of just 211 students (69.4\%) felt that alcohol is used as an emotional companion.(Fig-1)

Table-1 Showing the attitude of college students about alcohol consumption

\begin{tabular}{|l|c|c|c|}
\hline $\begin{array}{l}\text { ATTITUDE TOWARDS } \\
\text { ALCOHOL } \\
\text { CONSUM PTION }\end{array}$ & YES & NO & $\begin{array}{c}\text { NO } \\
\text { RESPONSE }\end{array}$ \\
\hline Drive after drinking & $82(26.97 \%)$ & $218(71.7 \%)$ & $4(1.3 \%)$ \\
\hline Considers safe to drink & $188(61.84 \%)$ & $116(38.1 \%)$ & $0(0 \%)$ \\
\hline Wants to stop drinking & $83(27.3 \%)$ & $219(72.03 \%)$ & $2(0.65 \%)$ \\
\hline Tried quitting & $74(24.34 \%)$ & $225(74.01 \%)$ & $5(1.64 \%)$ \\
\hline $\begin{array}{l}\text { Aware of harmful } \\
\text { effects }\end{array}$ & $1050(91.30 \%)$ & $87(7.56 \%)$ & $13(1.13 \%)$ \\
\hline
\end{tabular}

Figure -1 Showing attitude of youngsters towards alcohol consumption

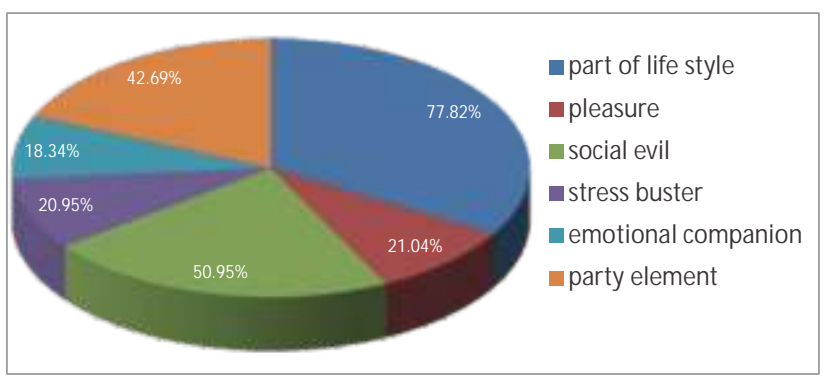

Discussion :

More than quarter of those consuming alcohol admit that they drive after drinking and most of them are involved in

\section{Reference:}

1. Attitude on alcohol and drinking pattern on youth by Killibarda B.et.al . page 67,68 .

2. Child and youth drinking novascotia health promotion and protection by T.schrans,DLT Schellnek,ZonYi page (iii)

3. Positive future by Simon Talbot and Prof.Tim Crabbe, Substance page2

4. Awareness and practices of road safety measures among undergraduate medical students in a South Indian state Awareness and practices of road safety measures among undergraduate medical students in a South Indian state V Kulkarni et al. J Forensic Leg M ed 2013 may

5. J Forensic Leg M ed 2013 may
RTAs or other legal issues. Study conducted by V Kulkarni et.al. Provides similar results of drunken driving among undergraduate students ${ }^{4}$.Vast majority of people consuming alcohol believe that it is a safe practice. More than quarter of this group states that they want to stop drinking and most of them have tried quitting. More than $90 \%$ of the total population studies are well aware of the harmful effects of alcohol. A small proportion of those who consume alcohol are also aware of its ill effects. The level of awareness among developed nations, according to their studies, is higher than that of our population. Studies have shown that students who see their friends drinking on various public portals also get influenced into drinking and smoking. Hence portals like face book and orkut are also becoming a new recent for the increasing alcohol trends in youngsters. It proves itself to be an indirect form of peer pressure where the students indulge themselves in alcohol habits.

\section{Conclusion :}

After assessing the result we can conclude that the students are well informed and they know the ill effects of alcohol consumption even though, most of them consider it as a part of life style.

\section{Acknowledgments:}

We sincerely thank the management of all colleges under NITTE University to grant us permission to carry out this survey. We thank Dr. Uday Kiran, Head of Department, Community Medicine, KSHEMA and his staff for their indispensable support. 